\title{
The Role of the Campus Visit and the Summer Orientation Program in the Modification of Student Expectations About College
}

Wren Singer

In the United States today only $47.6 \%$ of students graduate from the college or university at which they first enrolled (Durhams, 2000). The other 52.4\% transfer to other colleges or drop out of the higher education system. Why is this happening? One college student answers the question this way: "For some reason, this college isn't exactly what I had pictured, so I am not really happy here" (Boyer, 1987, p. 45). This quote epitomizes one of the reasons new students cite for leaving college: unmet expectations. "Too often we forget that students come to us with uninformed expectations about college learning and college life- another factor contributing to attrition" (Levitz \& Noel, 1989, pp. 68). Bean (1990) agreed "one fairly constant finding is that students leave school because they do not fit in. They may not fit in socially or academically or religiously or economically or for some other reasons, they leave because the school is not a good match for their needs" (p. 149).

Students form their expectations of college from many sources, including popular media, parents, friends, high school counselors, and indirect and direct communication from the university. Among these factors, the most direct one that an individual institution can influence is its own intentional communications with students. Given the evidence that unmet expectations are one of the reasons students cite for leaving a particular university, what are institutions intentionally doing to help students form more realistic expectations about what they will find at their institution?

Research examining college student attrition advises that the first year student's most critical transition period occurs during the first semester, therefore programs and services designed to combat student attrition should be front-loaded (Tinto, 1988). However, even before the first year student attends a class, the university has two opportunities to convey realistic expectations of college life: the campus visit and the summer orientation program. Both programs are ideally positioned to purposively modify and shape student expectations about the university experience.

The campus visit is a variable that predicts college selection and is a tool used by students during the college choice process. Gasperetti (1974) concluded that "the campus visit has a vital role to play in the decision making process for new applicants. Indeed, it is the fundamental step for an eventual commitment to apply for admissions to college by many students" (p. 19). While a number of studies substantiate the

Wren Singer is the Director of Orientation and New Student Programs at the University of WisconsinMadison. A complete copy of study findings are available through Singer, J. W. (2001). The role of the campus visit and the summer orientation program in the modification of student expectations about college life. Unpublished doctoral dissertation, University of Wisconsin-Madison. 
correlation between visiting campus and enrollment, there are few that examine the ability of the campus visit to convey clear expectations about college life. Magolda's (2000) qualitative examination of the campus visit concluded that the campus tour, while a fairly routine ritual, is a powerful tool for conveying cultural messages to prospective students. However, the extent to which prospective students on the tour received the messages "sent" through the program is not addressed.

The ability of orientation programs to modify unrealistic expectations was tested by Krallman and Holcomb (1997). Students' expectations about college were assessed before and after attending orientation at Miami University in Ohio. Results indicated that student' expectations in a number of key academic, social and personal areas changed after their orientation experience.

\section{Method}

The purpose of this study was first to identify the messages being conveyed to prospective students, and to determine how students' expectations about these messages were modified due to their campus visit and orientation program. Program personnel from UW-Madison were surveyed to determine the core messages they intended to convey through the programs. After the messages were identified, students were surveyed before and after attending the programming to determine the impact on their expectations. UW-Madison's programming is similar to that used nationally at large universities (Strumpf \& Sharer, 1993), making the results of this study applicable to similar institutions.

\section{Identification of themes}

Focus groups, surveys, program observation and document review were used to isolate the message "themes" conveyed through the campus visit and orientation program. First, focus groups were conducted with program employees to explore what these individuals hoped to convey through the visit and the orientation program. Second, 14 higher-level planners of the visit and orientation programs completed questionnaires about what they hoped to convey to students during the programs. In order to supplement and triangulate data gathered from the employees and the planners, the researcher observed a full session of the campus visit and orientation program and reviewed all printed documents that students received prior to and during the programs. The data were coded and categorized into themes, then the complete data set was reviewed to determine how many times each theme appeared in the data. The themes that were most often present were designated as the strongest themes for the program.

\section{Modification of student expectations}

A survey was designed to measure the ability of the visit and orientation program to modify student expectations related to the themes the programs intended to convey. 
Between one and five questions were developed to measure expectations related to each of the themes. Responses to the questions were measured on a seven point Likert-type scale.

Baseline measurement consisted of results from 497 students who were surveyed before their on-site visit began. The group consisted of high school students who were at the UW-Madison campus to attend a formal campus visit. For a two-week period every student attending a campus visit received a survey. Four hundred and ninety seven surveys were returned, for a response rate of $76.5 \%$. The sample was not random, but there is no evidence that students who attended the campus visit during this two-week period were different from students who attended the campus visit at any other time during the spring semester.

The second group was surveyed after their visit and before summer orientation. The surveys for this group were mailed to 1,000 randomly selected students after they made a reservation to attend the orientation program. Four hundred and twenty-nine surveys were returned for a response rate of $42.9 \%$. Sixty percent of this group had attended a campus visit.

A final 600 students were surveyed after summer orientation on four randomly selected dates. Four hundred and ninety-seven surveys were returned and used for the data analysis, for a response rate of $82.8 \%$. Sixty-five percent of the sample had attended a campus visit; it was coincidental that the first and third groups had exactly the same number of returned surveys.

The data gathered from the survey was analyzed using linear trend analysis and analysis of variance. All tests used an alpha of .05.

\section{Results}

\section{Identification of themes}

The analysis of the program employee/planner focus groups and questionnaires yielded 13 themes that the campus visit and the orientation program intend to convey to students. The themes are presented in Table 1. In addition, the analysis of the strength of the themes in the data yielded two leading themes for each program. The strongest themes for each program have been designated with an asterisk in Table 1. Strength was determined by noting how many times a theme appeared in the complete data set.

\section{Modification of expectations}

Overall results showed that expectations on eight of 13 themes were modified in the university-desired direction over the course of the three measurements. Table 2 illustrates this result.

An examination of demographic interactions illustrate that female students showed a greater fluctuation in their self-confidence over the course of the three measurements, and showed significantly less self-confidence than males at the final measurement. 
Figure 1 depicts this interaction. Secondly, students of color who did not visit the campus showed less awareness of the variety of campus options than white students who did not visit and students of color who did visit. This effect was significant at the measurement taken between the visit and orientation. Figure 2 depicts this interaction.

\section{Conclusions}

1. The campus visit and the orientation program may be effective in modifying student expectations about college on a number of factors. Students showed change in the university-desired direction on eight of 13 factors over the course of the three measurements. While this does not prove a causal relationship between attending the programs and changing expectations, it is encouraging to see that expectations are changing in the desired direction over the course of this critical transition period. Clearly there are other, uncontrollable, factors at play, such as messages from family, friends, and the media, but it would take a creative researcher to isolate the impact of the programs without denying students the chance to attend these programs. Because UW-Madison shares a similar orientation philosophy to other large research institutions (Strumpf \& Sharer, 1993), these results may suggest how students are reacting to messages conveyed by a variety of similar institutions.

2. Programs are trying to communicate too much. The results demonstrate that the campus visit and orientation programs at UW-Madison may be trying to communicate too much information for the new students to absorb. The university is attempting to convey 13 core messages to students during a campus visit that lasts three hours and a summer orientation and registration visit that lasts 24 hours. The fact that two of the most complex and critical themes, personal responsibility and respect for others, did not show significant change in any of the analyses performed may be an indication that students are not ready to process these complex behavioral and developmental concepts at this stage. Consequently, institutions should strive for quality over quantity and pare down the messages they intend to convey to students through visits and orientation.

3. Expectation development varies for demographic sub-groups. One of the most important findings to emerge from this research is the advantage of attending a campus visit for students of color. The students of color who did not visit showed less awareness of UW-Madison's many options than students of color who did visit. Additionally, among non-visitors, students of color showed less awareness of options than white students. Clearly students of color who do not visit the campus lack access to effective information communication channels to tell them about what is available at UWMadison.

\section{Implications for Program Administration}

1. Implement outcome based program evaluations. The evaluation of the visit and the orientation program should inform the university about how effective the program is at conveying its core messages. Current evaluation methods for the visit and orientation 
focus primarily on students' satisfaction with the program (Wiese, 2000). In order to fully understand the impact of the programs it is critical to assess knowledge and messages that students take from the programs. Customer service elements of current evaluations should be supplemented with learning outcome assessment questions.

2. Encourage students of color to attend campus visits. The results showed that students of color who do not visit have less awareness of UW-Madison's many options than students of color who do visit and white students who do not visit. Perhaps students of color have less awareness of the many options offered by UW-Madison because they have fewer informal opportunities to learn about UW-Madison. If the university is not able to encourage more students of color to visit campus, then alternative measures of conveying the variety of options available should be developed for students.

3. Help females maintain confidence in their ability to succeed. The results demonstrated that after attending orientation females had significantly less confidence in their ability to succeed at UW-Madison than males, and it is unclear what the impact of this finding might be. Perhaps females have a more difficult transition to college because they are less sure of themselves, or perhaps the lower confidence levels cause females to work harder during their first few semesters. The effect of this result might be partially understood by comparing first semester GPAs of males and females. For example, at UW-Madison, the GPA of first semester females in 2001 was 3.133 and first semester males was 2.996, indicating that perhaps females students are working harder during their first semester. Regardless, it is important for institutions to recognize that there are gender differences in the way that students experience visits and orientation programming.

In conclusion, this research used a wide variety of qualitative and quantitative techniques to understand what messages UW-Madison hopes to convey to new students and how new students' expectations change over the course of the pre-matriculation period. Some promising and interesting results were gathered and explained that appear to apply nationally, but plenty of room is left for future research examining the development and modification of student expectations about college. In order to increase the percentage of students who remain at the college where they began, universities must help students develop clear expectations about the college experience during the pre-matriculation period. 


\section{References}

Bean, J. P. (1990). Why students leave: insights from research. In D. Hossler and J. Bean (Eds.), The Strategic Management of College Enrollments (pp. 147-169). San Francisco: Jossey-Bass Publishers.

Boyer, E. L. (1987). College the undergraduate experience in America. New York: Harper and Row.

Durhams, S. (June 2, 2000). UW graduation rate nears record. Milwaukee Journal Sentinel.pp. 7.

Gasperetti, J.A. (1974). The admissions impact of the campus visit by prospective students. Journal of the National Association of College Admissions Counselors 19(2), 19-20.

Krallman, D., \& Holcomb, T. (1997). First-year students expectations: pre- and post-orientation. Buena Vista, FL: Association of Institutional Research.

Levitz, R., \& L. Noel (1989). Connecting students to institutions: keys to retention and success. In M. L. Upcraf and J. N. Gardner (Eds.), The Freshman Year Experience (pp. 65-81). San Francisco: Jossey-Bass Publishers.

Magolda, P. M. (2000). The campus tour: ritual and community in higher education. Anthropology and Education Quarterly 31(1), 24-46.

Strumpf, G., \& G. Sharer (1993). Trends and issues in orientation programs. In M. L. Upcraf (Ed.)., DesigningSuccessful Transitions: A Guide for Orienting Students to College (pp. 27-35). Columbia, SC: , National Resource Center for the Freshman Year Experience.

Wiese, D. (2000). The assessment and evaluation of orientation programs: a practical approach. In M. J. Fabich (Ed.), Orientation Planning Manual (pp. 52-58).

Pullman, WA: National Orientation Directors Association. 


\section{Themes UW-Madison attempts to communicate through visits and orientation}

1. UW-Madison provides many options (* visit)

2. UW-Madison will begin to feel smaller

3. Find academic/social balance

4. Basic knowledge about UW-Madison

5. Academic work is challenging

6. Support is available $(*$ orientation)

7. Personal responsibility (* orientation)

8. Respect for others

9. Take care of yourself and others

10. Students change and develop

11. Pride in UW-Madison (*visit)

12. Confidence in self

13. Learning occurs outside of the classroom

TABLE 2

\section{Means for linear trends}

\begin{tabular}{|c|c|c|c|c|c|}
\hline & & Pre-visit & $\begin{array}{l}\text { Between } \\
\text { visit and } \\
\text { orientation }\end{array}$ & $\begin{array}{l}\text { Post- } \\
\text { orientation }\end{array}$ & Significant \\
\hline & Factor & Group 1 & Group 2 & Group 3 & Positive Trend \\
\hline & & $\mathrm{N}=497$ & $\mathrm{~N}=429$ & $\mathrm{~N}=497$ & \\
\hline 1 & UW-Madison provides many options & 20.29 & 21.28 & 20.76 & $*$ \\
\hline 2 & UW-Madison will begin to feel smaller & 8.23 & 8.33 & 9.1 & $*$ \\
\hline 3 & Find academic/social balance & 2.31 & 2.1 & 2.07 & NS (negative) \\
\hline 4 & Basic knowledge about UW-Madison & 20.99 & 21.07 & 21.65 & $*$ \\
\hline 5 & Academic work is challenging & 10.14 & 10.64 & 10.98 & $*$ \\
\hline 6 & Support is available & 18.28 & 18.3 & 19.13 & $*$ \\
\hline 7 & Personal responsibility & 13.41 & 13.95 & 13.56 & NS \\
\hline 8 & Respect for others & 15.99 & 15.91 & 15.53 & NS (negative) \\
\hline 9 & Take care of yourself and others & 9.09 & 9.1 & 9.23 & * \\
\hline 10 & Students change and develop & 8.99 & 8.92 & 9.37 & * \\
\hline 11 & Pride in UW-Madison & 15.41 & 16.5 & 16.02 & * \\
\hline 12 & Confidence in self & 10.79 & 11.02 & 10.64 & NS \\
\hline 13 & Learning occurs outside of the classroom & 14.83 & 15.59 & 14.95 & NS \\
\hline
\end{tabular}

$*=$ Significant $\mathrm{p}<.10$

NS = non-significant

Negative $=$ non-significant negative trend 


\section{Confidence in self and gender}

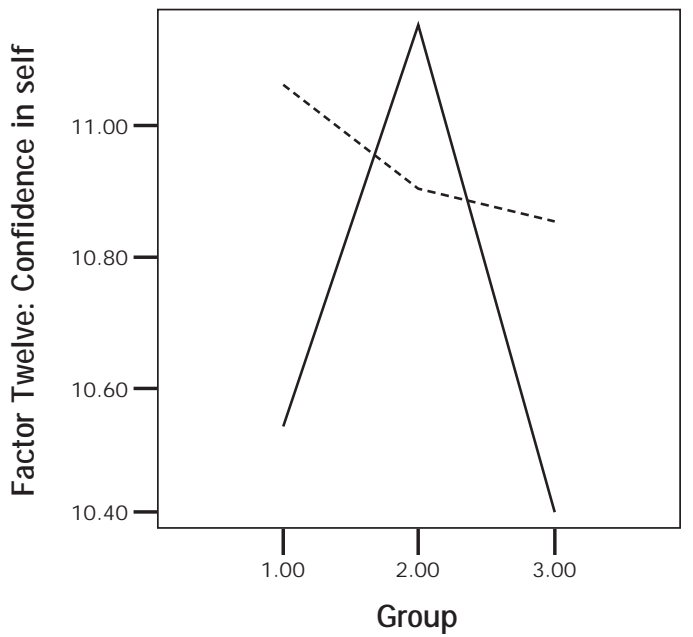

Dot/Lines show Means

\section{Gender}

Female $(\mathrm{N}=845)$

Male $(\mathrm{N}=532)$

\section{FIGURE 2}

\section{Race and awareness of university options}
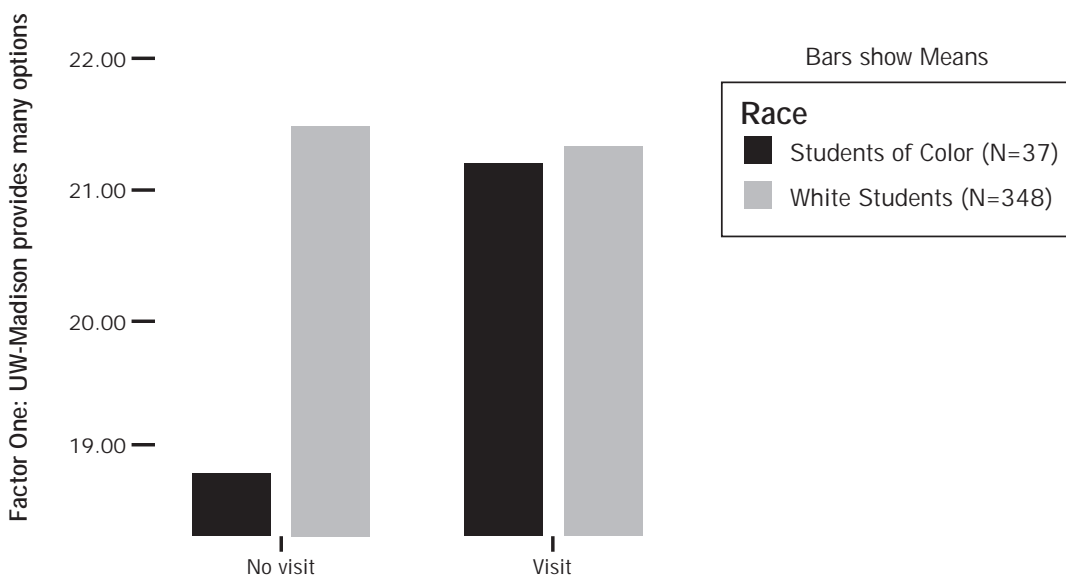